\title{
Air embolism secondary to endoscopy in hospitalized patients: results from the National Inpatient Sample (1998-2013)
}

\author{
Babatunde Olaiya ${ }^{a}$, Douglas G. Adler \\ Marshfield Clinic, Marshfield WI; University of Utah School of Medicine, Salt Lake City, Utah, USA
}

\section{Abstract}

\section{Introduction}

Air embolism occurs during endoscopic procedures when air is inadvertently introduced into the vasculature. Air embolism rarely complicates endoscopy; however, it entails

Department of a Internal Medicine, Marshfield Clinic, Marshfield WI

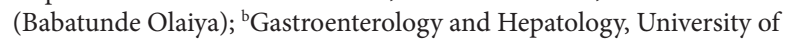
Utah School of Medicine, Salt Lake City, Utah (Douglas G. Adler), USA

Correspondence to: Douglas G. Adler MD, FACG, AGAF, FASGE, Professor of Medicine, Director of Therapeutic Endoscopy, Director, GI Fellowship Program, Gastroenterology and Hepatology, University of Utah School of Medicine, Huntsman Cancer Center, 30N 1900E 4R118, Salt Lake City, Utah 84132, USA, e-mail: Douglas.adler@hsc.utah.edu

Conflict of Interest: None

Received 8 May 2019; accepted 19 June 2019; published online 17 July 2019

DOI: https://doi.org/10.20524/aog.2019.0401 a high risk of leading to severe or even fatal outcomes if not diagnosed and treated promptly, and death can occur even with aggressive interventions to treat this problem $[1,2]$. Though most commonly associated with endoscopic retrograde cholangiopancreatography (ERCP), air embolism can complicate any endoscopic procedure [3-5].

Plausible mechanisms for air embolism following endoscopic procedures include, but are not limited to the following: insufflated air under pressure entering into an exposed vessel through a compromised mucosal barrier; mechanical manipulation of the bile ducts; the presence of biliary venous shunts; direct passage of air into the portal venous system during biliary manipulation; and inability of the pulmonary circulation to remove air emboli [6]. The risk of post-endoscopic air embolism appears to be increased by the following factors: a) biliary interventions; b) portosystemic shunts; c) hepatobiliary tumors; d) blunt/penetrating trauma to the liver; e) high pressure insufflation; and f) inflammatory lesions, including hepatic abscess, inflammatory bowel disease, and mesenteric ischemia [7-10]. 
The true incidence of air embolism is difficult to ascertain. Most studies of air embolism in the literature are case reports and there is a paucity of data on the incidence of post-endoscopic air embolism, especially in hospitalized patients. The aim of this study was to describe the incidence and outcomes of air embolism after inpatient endoscopic procedures in the United States during the 16-year period from 1998-2013, using a large national database: the National Inpatient Sample (NIS).

\section{Patients and methods}

\section{Data source}

Study data were obtained from the NIS database, the largest publicly available all-payer inpatient healthcare database in the United States. It has a weighted national estimate in excess of 35 million admissions annually. Its large sample size is ideal for developing national and regional estimates, and enables analyses of rare conditions, uncommon treatments, and special populations [11]. It has been used and validated in several studies to report reliable estimates of the burden and outcomes of gastrointestinal diseases [12-15].

\section{Study sample}

We queried the database for all endoscopic procedures using the International Classification of Diseases, $9^{\text {th }}$ revision, Clinical Modification (ICD-9-CM) coding system. ICD -9-CM codes used to extract relevant data are listed in Supplementary Table 1 .

\section{Diagnosis of post-endoscopic air embolism}

There is no ICD-CM-9 code that specifically applies to air embolism secondary to endoscopy. Therefore, we adopted a retrospective cohort design to identify cases. This methodology has been utilized/validated by other studies referencing the NIS to study the incidence of procedure-related gastrointestinal disorders [12,16]. After ICD-CM-9 codes 999.1 (air embolism to any site following infusion, perfusion, or transfusion) and 958.0 (traumatic air embolism) had been used to identify preliminary cases, the selection was refined by including only cases that had an endoscopy as an index procedure during hospitalization. For the purposes of this study, post-endoscopic air embolism was defined as an ICD-CM-9 code for a diagnosis of air embolism that occurred in cases with an endoscopy as the index procedure during hospitalization.

\section{Other study variables}

For each record, an estimate of premorbid condition was calculated using the Charlson Comorbidity Index [17]. This is a
Table 1 Population baseline characteristics and type of endoscopy

\begin{tabular}{|c|c|c|}
\hline Characteristics & (n) & (\%) \\
\hline \multicolumn{3}{|l|}{ Gender } \\
\hline Male & 979775 & 43.6 \\
\hline Female & 1264471 & 56.3 \\
\hline \multicolumn{3}{|l|}{ Race } \\
\hline White & 1279653 & 57.0 \\
\hline African American & 398212 & 17.7 \\
\hline Hispanic & 283154 & 12.6 \\
\hline Asia-Pacific & 207911 & 9.2 \\
\hline Others & 76361 & 3.4 \\
\hline Age (M (SD) years & $62.5(19.4)$ & \\
\hline \multicolumn{3}{|l|}{ Endoscopy } \\
\hline EGD & 1804899 & 80.4 \\
\hline Colonoscopy & 263114 & 11.7 \\
\hline Sigmoidoscopy & 56736 & 2.5 \\
\hline ERCP & 120542 & 5.4 \\
\hline \multicolumn{3}{|l|}{ Admission type } \\
\hline Non-elective & 2040970 & 90.9 \\
\hline Elective & 204321 & 9.1 \\
\hline \multicolumn{3}{|l|}{ Hospital location } \\
\hline Urban & 1998309 & 88.9 \\
\hline Rural & 246983 & 11.1 \\
\hline \multicolumn{3}{|l|}{ Hospital region } \\
\hline North East & 435586 & 19.4 \\
\hline Midwest & 520908 & 23.2 \\
\hline Southern & 902607 & 40.2 \\
\hline West & 386190 & 17.2 \\
\hline
\end{tabular}

SD, standard deviation; ERCP, endoscopic retrograde

cholangiopancreatography; EGD, esophagogastroduodenoscopy

scoring system for predicting mortality by weighting comorbid conditions; it has been used in several studies to measure the burden of disease [18-20].

\section{Study outcomes}

Our primary outcome of interest was the incidence of air embolism after endoscopy. All-cause inpatient mortality after endoscopy was measured as a secondary outcome.

\section{Statistical analysis}

Categorical and continuous variables were expressed using frequencies, proportions, measures of central tendency as well as standard deviation. We used the chi-square test to assess differences between categorical variables. Effect sizes 
were quantified using odds ratios (OR) with 95\% confidence intervals (CI). Binary logistic regression was used to explore the effect of air embolism on inpatient mortality after controlling for covariates. Missing cases were excluded from analysis. The level of significance for all tests was $\mathrm{P}<0.05$. All analyses were performed using SPSS software (IBM Corp. Released 2017. IBM Statistics for Macintosh, Version 25.0. Armonk, NY).

\section{Results}

\section{Patient demographics and hospital characteristics}

We identified 2,245,291 endoscopies that were performed as index procedures on hospitalized patients in the United States between 1998 and 2013. A total of 1,264,471 patients (56\%) were female and 1,279,653 (57\%) were Caucasians. Mean age at the time of procedure was 62.5 years. Nearly all hospitalizations were non-elective admissions (91\%). Similarly, most hospitalizations/endoscopic procedures $(89 \%)$ occurred in urban hospitals. Most patients were treated in the South (35\%) and Midwest (20\%) regions (Table 1).

\section{Endoscopic procedures}

EGD was the most common endoscopic procedure, accounting for $80 \%$ of endoscopic procedures. Colonoscopy, ERCP and sigmoidoscopy accounted for $12 \%, 5.5 \%$, and $2.5 \%$ of procedures, respectively. A higher proportion of lower gastrointestinal procedures-i.e., sigmoidoscopy (67.5\%) and colonoscopy $(69.7 \%)$-occurred in patients older than 60 years of age compared to ERCP and EGD.

\section{Post-endoscopic air embolism}

Post-endoscopic air embolism occurred in 13 cases, producing a rate of 0.57 per 100,000 endoscopic procedures. Per procedure, air embolism was most common after ERCP, occurring in 3.32 per 100,000 procedures, compared with 0.44 and 0.38 per 100,000 procedures for EGD and colonoscopy, respectively $(\mathrm{P}<0.05)$. We recorded no cases of air embolism after sigmoidoscopy. The mean age of patients with air embolism was $49.5 \pm 20.5$ years. The primary diagnoses in cases that developed post-endoscopic air embolism are presented in Table 2. On bivariate analysis, ERCP was the only endoscopic procedure significantly associated with post-endoscopic air embolism (OR 7.45, 95\%CI 2.25-24.86; $\mathrm{P}<0.001$ ) (Table 3).

\section{Inpatient mortality}

Inpatient mortality after endoscopy was $1.4 \%$. Patient and hospital characteristics were significantly associated with inpatient mortality included age, sex, race, comorbid status and payer type (Table 4).

For patients who had an air embolism after endoscopy, the case fatality rate was $15.4 \%$. On bivariate analysis, post-endoscopic air embolism was significantly associated with greater odds of inpatient mortality (OR 12.85, 95\%CI 2.85-58.01; $\mathrm{P}=0.01$ ). After adjusting for covariates, the occurrence of air embolism after endoscopy was an independent predictor of inpatient mortality (OR 10.35, 95\%CI 1.21-88.03; $\mathrm{P}<0.03$ ) (Table 4).

\section{Discussion}

Air embolism is usually an iatrogenic phenomenon. In some cases, it runs a subclinical course and is probably

Table 2 Diagnosis and demographics for air embolism cases

\begin{tabular}{|c|c|c|c|c|c|c|}
\hline & Diagnosis & Sex & Age & Procedure type & Admission to procedure (days) & Outcome \\
\hline 1 & Internal hemorrhoids with complicated NEC & M & 73 & Colonoscopy & 5 & Alive \\
\hline 2 & Dyskinesia of esophagus & M & 38 & EGD & 0 & Alive \\
\hline 3 & Crohn's disease & $\mathrm{F}$ & 31 & EGD & 7 & Alive \\
\hline 4 & Obstruction of biliary duct & $\mathrm{F}$ & 59 & ERCP & 0 & Alive \\
\hline 5 & Obstruction of biliary duct & M & 28 & ERCP & 13 & Alive \\
\hline 6 & Poisoning by other medications/drugs & M & 60 & EGD & 0 & Alive \\
\hline 7 & Chronic gastric ulcer with hemorrhage & M & 83 & EGD & 6 & Alive \\
\hline 8 & Choledocholithiasis with obstruction & $\mathrm{F}$ & 42 & ERCP & 1 & Deceased \\
\hline 9 & Hepatic laceration & $\mathrm{F}$ & 32 & ERCP & 5 & Deceased \\
\hline 10 & Complications of lung transplant & $\mathrm{F}$ & 33 & EGD & * & Alive \\
\hline 11 & Foreign body in stomach & $\mathrm{F}$ & 87 & EGD & 4 & Alive \\
\hline 12 & Gastritis & M & 39 & EGD & 1 & Alive \\
\hline 13 & Unspecified chest pain & $\mathrm{F}$ & 39 & EGD & 0 & Alive \\
\hline
\end{tabular}


underdiagnosed [4,21]. However, severe cases often manifest with cardiopulmonary and cerebrovascular symptoms and are associated with high morbidity and mortality outcomes. While neurologic sequelae appear to be more common, cases with cardiopulmonary symptoms are at a greater risk of death [22].

Table 3 Odds of air embolism by endoscopy type

\begin{tabular}{lcccc}
\hline Endoscopy type & Odds ratio & \multicolumn{2}{c}{$95 \% \mathrm{CI}$} & P-value \\
\hline EGD & 0.39 & 0.13 & 1.19 & 0.15 \\
Colonoscopy & 0.86 & 0.11 & 6.86 & 0.88 \\
ERCP & 7.46 & 2.25 & 24.86 & 0.001 \\
Sigmoidoscopy & & & \\
${ }^{*}$ No recorded cases of air embolism \\
$\begin{array}{l}\text { CI, confidence interval; ERCP, endoscopic retrograde } \\
\text { cholangiopancreatography }\end{array}$
\end{tabular}

Studies show mortality rates due to air embolism range from $12-30 \%$, comparable to our finding of $15.4 \%$. More than half of these patients die within the first $48 \mathrm{~h}[22,23]$.

In comparison to surgical or endovascular interventions, air embolism rarely complicates endoscopy. McCarthy et al observed that endoscopy accounted for only 2 of 67 cases of air embolism over a 25-year period of hospital records [22]. Likewise in this study, we observed that air embolism complicated approximately 1 in 175,000 endoscopic procedures. The risk for air embolism was, however, higher in ERCP procedures, being 7.5- and 8.8-fold greater compared to EGD and colonoscopy, respectively. Furthermore, ERCP was the only endoscopic procedure significantly associated with developing an air embolism (OR 7.45, 95\%CI 2.25-24.86; $\mathrm{P}<0.001)$. This finding is well described in the literature, and may be explained by air entering the arterial or venous system of the liver during ERCP maneuvers [4].

Table 4 Logistic regression estimating the effect of air embolism on inpatient mortality

\begin{tabular}{|c|c|c|c|c|}
\hline Variable & Odds Ratios & \multicolumn{2}{|c|}{$95 \% \mathrm{CI}$} & P-value \\
\hline \multicolumn{5}{|l|}{ Sex } \\
\hline Female & 1 & & & \\
\hline Male & 1.43 & 1.39 & 1.47 & 0.001 \\
\hline \multicolumn{5}{|l|}{ Race } \\
\hline White & 1 & & & \\
\hline Non-White & 1.06 & 1.03 & 1.09 & 0.001 \\
\hline \multicolumn{5}{|l|}{ Charlson score } \\
\hline 0 & 1 & & & \\
\hline 1 & 1.13 & 1.08 & 1.17 & 0.001 \\
\hline $2+$ & 2.14 & 2.07 & 2.20 & 0.001 \\
\hline Age (continuous) & & 1.035 & 1.034 & 1.036 \\
\hline \multicolumn{5}{|l|}{ Admission type } \\
\hline Elective & 1 & & & \\
\hline Emergent & 0.97 & 0.92 & 1.02 & 0.29 \\
\hline \multicolumn{5}{|l|}{ Hospital location } \\
\hline Urban & 1 & & & \\
\hline Rural & 1.03 & 0.99 & 1.08 & 0.94 \\
\hline \multicolumn{5}{|l|}{ Hospital region } \\
\hline North-East & 1 & & & \\
\hline North-East & 0.77 & 0.74 & 0.81 & 0.001 \\
\hline South & 0.89 & 0.86 & 0.92 & 0.001 \\
\hline West & 0.96 & 0.92 & 1.01 & 0.12 \\
\hline \multicolumn{5}{|l|}{ Insurance type } \\
\hline Private & 1 & & & \\
\hline Non-private & 1.16 & 1.11 & 1.21 & 0.001 \\
\hline \multicolumn{5}{|l|}{ Air embolism } \\
\hline No & 1 & & & \\
\hline Yes & 10.35 & 1.21 & 88.03 & 0.03 \\
\hline
\end{tabular}


Compared to diagnostic ERCP, therapeutic ERCPs involve more invasive and aggressive instrumentation of the biliary system and entail a higher risk for air embolism [24]. It is believed that a combination of high pressure from air insufflation and mechanical trauma to the bile ducts by instruments during therapeutic ERCP could potentiate entry of air into the circulation through the biliary tree.

Albert et al observed that the use of small-diameter endoscopes and air insufflation for direct intraductal biliary endoscopy promotes the development of air embolism [25]. The authors strongly recommended that only $\mathrm{CO}_{2}$ be used for insufflation during intraductal biliary endoscopy.

Though air embolism even with $\mathrm{CO}_{2}$ has been documented, $\mathrm{CO}_{2}$ has been shown to have an overall better safety profile as compared to room air $[4,8,26]$. $\mathrm{CO}_{2}$ was also recommended in a recent report by the American Society for Gastrointestinal Endoscopy's technology committee [27].

Air embolism can occur even with an intact mucosal barrier [28]. However, a pre-existing breach in the gastrointestinal mucosa is a commonly implicated factor in developing air embolism after endoscopy. The first reported case of endoscopy-related cerebral air embolism occurred during an EGD and involved a patient with a duodenal ulcer and duodenocaval fistula [29]. Other reported cases of air embolism after endoscopy include perforated gastric ulcer, esophageal biopsy, Crohn's disease with fistulas and erosive esophagitis [8,30-32]. Similarly, in our study we demonstrate that most cases of air embolism after endoscopy occurred in relation to gastrointestinal disorders involving a breach to the gastrointestinal mucosa or vasculature (Table 2). Therefore, it is imperative for endoscopists to maintain a high index of suspicion for air embolism when performing endoscopy involving these gastrointestinal disorders.

In this study, we report an all-cause inpatient mortality rate of $1.4 \%$. In addition, we observed that the risk of inpatient mortality was much higher in patients with more comorbidities. The case fatality rate after air embolism was $15.4 \%$. After controlling for comorbidities amongst other relevant factors, we observed that air embolism after endoscopy independently increased the risk of inpatient mortality. This finding underscores the need for increased awareness of air embolism during endoscopy and the prompt implementation of appropriate therapeutic measures when air embolism is diagnosed.

Air embolism can be considered in the differential diagnosis when patients experience unexpected, sudden and significant hemodynamic instability during endoscopy. Prompt supportive treatment, including resuscitation and high-flow oxygen (if not already being delivered) and cardiopulmonary support as needed, should be implemented, even before air embolism is confirmed if the level of suspicion is high. Fluid resuscitation increases central venous pressure and may prevent further entry of air into the venous system. Hyperbaric oxygen therapy may improve outcomes in patients with cerebral air embolism [33].

Our study has several limitations, most of which are inherent to the administrative nature of the NIS database. While the NIS is an established database used in many published analyses, it is subject to data misclassification, incomplete documentation, and other coding difficulties. Furthermore, the NIS applies only to an inpatient population and our findings cannot be generalized to the overall population. The NIS lacks data on the severity of gastrointestinal disease and we could therefore not include this in our analysis. However, despite these limitations, most of our study findings are consistent with the previous literature.

In conclusion, air embolism after endoscopy is rare. However, it has a high potential for adverse outcomes and its occurrence independently predicts patient mortality. Endoscopists should maintain increased awareness for air embolism, especially in patients undergoing high-risk procedures like therapeutic ERCP. Larger studies are needed to quantify the risk of postendoscopic air embolism, especially in disorders that involve a breach in the gastrointestinal mucosa.

\section{Summary Box}

\section{What is already known:}

- Air embolism is most commonly associated with endoscopic retrograde cholangiopancreatography (ERCP) procedures

- Patients who have air embolism are at very high risk of death

- Disorders with a breach to the gastrointestinal mucosa predispose to post-endoscopic air embolism

\section{What the new findings are:}

- Post-endoscopic air embolism occurs in approximately 0.57 per 100,000 endoscopic procedures

- ERCP is the only endoscopic procedure significantly associated with developing post-endoscopic air embolism

- Air embolism is an independent predictor of mortality, irrespective of comorbid status

\section{References}

1. Lowdon JD, Tidmore TL. Fatal air embolism after gastrointestinal endoscopy. Anesthesiology 1988;69:622-623.

2. Truyols C. Fatal air embolism after upper endoscopy in a 48-yearold man. Endoscopy 2012;44(Suppl 2 UCTN):E282.

3. Trabanco S, Pardo S, Williams M, Diaz J, Ruiz C. Cerebral air embolism after ERCP. J Clin Anesth 2017;36:133-135.

4. Donepudi S, Chavalitdhamrong D, Pu L, Draganov PV. Air embolism complicating gastrointestinal endoscopy: a systematic review. World J Gastrointest Endosc 2013;5:359-365.

5. Voigt P, Schob S, Gottschling S, Kahn T, Surov A. Systemic air embolism after endoscopy without vessel injury - A summary of reported cases. J Neurol Sci 2017;376:93-96.

6. Thackray NM, Murphy PM, McLean RF, deLacy JL. Venous air embolism accompanied by echocardiographic evidence of transpulmonary air passage. Crit Care Med 1996;24:359-361. 
7. Lamparter S, Goecke W, Koehler HH. Hepatic portal venous gas after upper endoscopy in a patient with a gastrointestinal stromal tumor. J Clin Ultrasound 2009;37:401-402.

8. Katzgraber F, Glenewinkel F, Fischler S, Rittner C. Mechanism of fatal air embolism after gastrointestinal endoscopy. Int J Legal Med 1998;111:154-156.

9. Finsterer J, Stöllberger C, Bastovansky A. Cardiac and cerebral air embolism from endoscopic retrograde cholangio-pancreatography. Eur J Gastroenterol Hepatol 2010;22:1157-1162.

10. Bisceglia M, Simeone A, Forlano R, Andriulli A, Pilotto A. Fatal systemic venous air embolism during endoscopic retrograde cholangiopancreatography. Adv Anat Pathol 2009;16:255-262.

11. NIS Database Documentation. Available from: https://www.hcupus.ahrq.gov/db/nation/nis/nisdbdocumentation.jsp [Accessed 3 July 2019].

12. Schulman AR, Abougergi MS, Thompson CC. Assessment of the July effect in post-endoscopic retrograde cholangiopancreatography pancreatitis: Nationwide Inpatient Sample. World J Gastrointest Endosc 2017;9:296-303.

13. Wuerth BA, Rockey DC. Changing epidemiology of upper gastrointestinal hemorrhage in the last decade: a nationwide analysis. Dig Dis Sci 2018;63:1286-1293.

14. Barber GE, Hendler S, Okafor P, Limsui D, Limketkai BN. Rising incidence of intestinal infections in inflammatory bowel disease: a nationwide analysis. Inflamm Bowel Dis 2018;24:1849-1856.

15. Ramsey M, Krishna SG, Stanich PP, et al Inflammatory bowel disease adversely impacts colorectal cancer surgery short-term outcomes and health-care resource utilization. Clin Transl Gastroenterol 2017;8:e127.

16. Schulman AR, Gergi MA, Ryou M, Thompson CC. Mo1415 incidence and outcomes of post-ERCP pancreatitis during the academic year: is July dangerous? Gastrointest Endosc 2015;81:AB411-AB412.

17. Charlson ME, Pompei P, Ales KL, MacKenzie CR. A new method of classifying prognostic comorbidity in longitudinal studies: development and validation. J Chronic Dis 1987;40:373-383.

18. Baldwin L-M, Klabunde CN, Green P, Barlow W, Wright G. In search of the perfect comorbidity measure for use with administrative claims data: does it exist? Med Care 2006;44:745-753.

19. Myers RP, Quan H, Hubbard JN, Shaheen AA, Kaplan GG. Predicting in-hospital mortality in patients with cirrhosis: results differ across risk adjustment methods. Hepatology 2009;49:568-577.

20. Poses RM, McClish DK, Smith WR, Bekes C, Scott WE. Prediction of survival of critically ill patients by admission comorbidity. J Clin Epidemiol 1996;49:743-747.

21. Mirski MA, Lele AV, Fitzsimmons L, Toung TJ. Diagnosis and treatment of vascular air embolism. Anesthesiology 2007;106:164-177.

22. McCarthy CJ, Behravesh S, Naidu SG, Oklu R. Air embolism: diagnosis, clinical management and outcomes. Diagnostics (Basel) 2017 Jan 17;7.

23. Bessereau J, Genotelle N, Chabbaut C, et al Long-term outcome of iatrogenic gas embolism. Intensive Care Med 2010;36:1180-1187.

24. Afreen LK, Bryant AS, Nakayama T, et al Incidence of venous air embolism during endoscopic retrograde cholangiopancreatography. Anesth Analg 2018;127:420-423.

25. Albert JG, Friedrich-Rust M, Elhendawy M, Trojan J, Zeuzem S, Sarrazin C. Peroral cholangioscopy for diagnosis and therapy of biliary tract disease using an ultra-slim gastroscope. Endoscopy 2011;43:1004-1009.

26. Bonnot B, Nion-Larmurier I, Desaint B, et al Fatal gas embolism after endoscopic transgastric necrosectomy for infected necrotizing pancreatitis. Am J Gastroenterol 2014;109:607-608.

27. Lo SK, Fujii-Lau LL, Enestvedt BK, et al ASGE Technology Committee. The use of carbon dioxide in gastrointestinal endoscopy. Gastrointest Endosc 2016;83:857-865.

28. Chorost MI, Wu JT, Webb H, Ghosh BC. Vertebral venous air embolism: an unusual complication following colonoscopy: report of a case. Dis Colon Rectum 2003;46:1138-1140.

29. Christl SU, Scheppach W, Peters U, Kirchner T. Cerebral air embolism after gastroduodenoscopy: complication of a duodenocaval fistula. Gastrointest Endosc 1994;40:376-378.

30. McAree BJ, Gilliland R, Campbell DM, Lucas JW, Dickey W. Cerebral air embolism complicating esophagogastroduodenoscopy (EGD). Endoscopy 2008;40(Suppl 2):E191-E192.

31. Pandurangadu AV, Paul JA, Barawi M, Irvin CB. A case report of cerebral air embolism after esophagogastroduodenoscopy: diagnosis and management in the emergency department. J Emerg Med 2012;43:976-979.

32. Mittnacht AJ, Sampson I, Bauer J, Reich DL. Air embolism during sigmoidoscopy confirmed by transesophageal echocardiography. J Cardiothorac Vasc Anesth 2006;20:387-389.

33. Blanc P, Boussuges A, Henriette K, Sainty JM, Deleflie M. Iatrogenic cerebral air embolism: importance of an early hyperbaric oxygenation. Intensive Care Med 2002;28:559-563. 


\section{Supplementary Table}

Supplementary Table 1 Procedures and ICD-9-CM codes used for data selection

\begin{tabular}{|c|c|}
\hline Procedure & Code \\
\hline Flexible fiber optic colonoscopy & 45.23 \\
\hline Flexible sigmoidoscopy & 45.24 \\
\hline Esophagogastroduodenoscopy (EGD) & 45.13 \\
\hline Closed [endoscopic] biopsy of small intestine (brushing or washing for specimen collection) & 45.14 \\
\hline EGD with closed biopsy & 45.16 \\
\hline Endoscopic retrograde cholangiography & 51.11 \\
\hline Endoscopic retrograde cholangiopancreatography & 51.10 \\
\hline Endoscopic retrograde pancreatography & 52.13 \\
\hline Endoscopic biopsy of biliary duct or sphincter of Oddi & 51.14 \\
\hline Pressure measurement of sphincter of Oddi & 51.15 \\
\hline Endoscopic biopsy of pancreatic duct & 52.14 \\
\hline Cannulation of pancreatic duct & 52.92 \\
\hline Endoscopic dilation of ampulla and biliary duct & 51.84 \\
\hline Endoscopic insertion of nasobiliary drainage tube & 51.86 \\
\hline Endoscopic removal of stone from biliary tract & 51.88 \\
\hline Endoscopic insertion of nasopancreatic drainage tube & 52.97 \\
\hline Endoscopic insertion of stent into pancreatic duct & 52.93 \\
\hline Endoscopic sphincterotomy and papillotomy & 51.85 \\
\hline Endoscopic excision or destruction of lesion of biliary ducts or sphincter of Oddi & 51.64 \\
\hline Endoscopic excision or destruction of lesion or tissue of pancreatic duct & 52.21 \\
\hline Excision of other bile duct & 51.69 \\
\hline Endoscopic insertion of stent into bile duct & 51.87 \\
\hline Endoscopic removal of stone from pancreatic duct & 52.94 \\
\hline Endoscopic dilation of pancreatic duct & 52.98 \\
\hline
\end{tabular}

